\title{
A Restrictive Humanitarian Policy and the Wellbeing of the Disabled in Disasters in Kisumu County
}

\author{
Phitalis Were Masakhwe, Masinde Muliro University of Science and Technology, Kenya \\ Kennedy Onkware, Masinde Muliro University of Science and Technology, Kenya \\ Susan Kilonzo, Maseno University, Kenya
}

\begin{abstract}
This paper explores how PWD's well-being is realized in disaster situations in Kisumu County of Kenya. There is a significant population of 15,760 persons with disability across Kisumu County. Their well-being is protected by the international humanitarian policy. At the national level, the well-being of persons with disability is taken care of in the Disability Act 2003 and the National Disability Policy. Despite existence of a humanitarian policy framework, the well-being of the disabled is compromised in disaster situations within Kisumu County. The humanitarian policy framework limits humanitarian action to response, which compromises the well-being of PWD. The study employed semi-structured questionnaire instruments to gather information on humanitarian policies applicable to PWD in disaster context. From the key findings, the study concludes that the international humanitarian policies as well as national humanitarian policies are restrictive in nature. The policy lacks enforcement and implementation mechanisms to support the wellbeing of persons with disability in disasters.
\end{abstract}

\section{KEYWORDS}

Disaster, Humanitarian Policy Framework, International Humanitarian Policy, National Humanitarian Policy, Persons With Disability, UN Convention

\section{INTRODUCTION}

In situations of risk and humanitarian emergencies, the UN Charter on Inclusion of Persons with Disability stipulates that partner states have the responsibility to protect the well-being of persons with disability (UN, 2016). This charter, thus, provides a humanitarian framework for access to services and inclusion of Persons with disabilities in all aspects of life. It provides for the achievement of equalization to opportunities by prohibiting discrimination in employment, education and health. Kenya has ratified the International Convention on the Rights of Persons with Disability and the UN Charter on Inclusion of Persons with Disability. The international humanitarian policy expects inclusion of persons with disability into humanitarian action but it fails to indicate implementation 
mechanisms on the same. On the other hand, the national humanitarian policy calls for protection of persons with disability in disaster situations but fails to point out exactly how such protection is supposed to be achieved. The humanitarian policy framework is therefore restrictive in nature with regard to the well-being of person with disability in disasters.

At the national level, the rights of persons with disability are taken care of in the Disability Act, 2003 and the National Disability Policy. Kenya enacted the Persons with Disability Act of 2003 which came into force in June 2004. This Act provides a legislative framework for access to services and inclusion of Persons with disabilities in all areas of life. The act provides for the achievement of equalization to opportunities by elimination of discrimination in employment, education and health among others. On accessibility, the Act promotes accessibility of physical structures and to information of services to Persons with disabilities (Government of Kenya, 2003). This Act does not refer to the rights of persons with disability in disaster situations, and therefore, is restrictive. National Disability Policy (2009), however, in Article 11 addresses situations of risk and humanitarian emergencies of persons of disability during disasters. It also identifies the fact that different disabilities require specific approaches to meet their information and communication needs (Government of Kenya, 2009). Janzen et al., (2012), on the contrary, argues that the rights of person with disabilities are yet to be mainstreamed into humanitarian action. To illustrate this, Abonyo (2015), for example, the 2007 Post Election Violence and other humanitarian emergencies presented Kenya with unprecedented challenges on how to deal with person with disabilities. In the past, in most crises, the government's responses have consistently taken into account the special needs for the persons with disabilities by facilitating the provision of emergency aid and supplies to them in camps and host communities. Thus, this protection is limited to response stage alone. The gap in these studies is how persons with disability can participate in entire humanitarian action cycle so that their protection is adequate.

Despite existence of a humanitarian policy framework, the well-being of the disabled is compromised in disaster situations within Kisumu County because of lack of clarity on implementation of the policy. Statistics from the National Council for People with Disability indicate that a significant population of 15,760 people are disabled across Kisumu County. Their well-being is protected by the UN Conventions on the Rights of Disabled People (UNCRDP) and UN Charter on Inclusion of Persons with Disability during disasters. Further, the humanitarian policy framework limits humanitarian action to response to disasters thus protection of person with disability is compromised from pre-disaster stages. For example, during the 2007/2008 Post-Election Violence persons with disability struggled to find food and health services (Abonyo, 2015). Some suffered as a result of floods in Nyando since they were unable to escape from foods in 2015. The disabled escaped from foods by being carried on peoples or cattle backs at a fee since better evacuation means were non-existent (Supriya et al, .2018).

The humanitarian policy in its current form simply states that the rights of PWD need to be respected by them being included into humanitarian action. However, PWD as illustrated are yet to be protected as the policy states because of weakness on how exactly they are supposed to be protected at different points of humanitarian action. Therefore, humanitarian policy framework is inadequate in the sense that it restricts protection to humanitarian response and thus limits operations of humanitarian organizations to the same. Further, measures on removing these challenges are not captured from persons with disability perspective.

\section{MATERIALS AND METHODS}

The land area of Kisumu County totals $2085.9 \mathrm{~km}^{2}$. Kisumu County neighbours Siaya County to the West, Vihiga County to the North, Nandi County to the North East and Kericho County to the East. Its neighbour to the South is Nyamira County and Homa Bay County is to the South West. The county has a shoreline on Lake Victoria, occupying northern, western and a part of the southern shores of the Winam Gulf. The county has an annual relief rainfall that ranges between $1200 \mathrm{~mm}$ and $1300 \mathrm{~mm}$ in different sectors. The rain mainly falls in two seasons. Kisumu is 
known for its thunderstorms, which are the major type of precipitation and normally occur in mid-afternoon during the rainy season. Kisumu is warm throughout the year with a mean annual temperature of $23.0 \mathrm{C}$. The temperature ranges between $200 \mathrm{C}$ and $350 \mathrm{C}$ but seldom falls below $190 \mathrm{C}$. The climate of Kisumu County makes it vulnerable to floods in some areas such as nyando. The population of persons with disability and their households in Kisumu county is about15, 760 (National Council for People with disability, 2019). A section of this population was affected by post-election violence in 2007/8 (Abonyo, 2015). He argues that in this uncertainty some disabled persons were left behind as they struggled for safety, food, protection and recognition from the community. It was of much threat to life as more cases of physical disabilities were reported with others getting injured in the conflict. Nyakundi (2010) concurs that during the postelection violence more that $20 \%$ of disabled persons were faced with the challenge of accessing food from shopping centers due to protracted Post-Election violence Also, Kisumu County is affected by both natural and man-made disasters such as floods, political unrests among others. In November 2015, the Kenya Red Cross Society (KRCS) County response team was deployed to assist approximately 1,200 people affected by floods. CBM (2018) report indicates that during floods, older people and people with disabilities were carried to safety on someone's back or transported in a cart for a fee. The study employed semi-structured questionnaire instruments to gather information on humanitarian policies applicable to PWD in disaster context. It was used with humanitarian officers-98 and government officers-98. The researcher adopted semistructured interviews with open-ended questions which were employed as one of the methods for data collection to provide qualitative data and were complemented by the quantitative data. The researcher used interviews with the regional director of Kenya Red Cross Society (1), regional directors of UN agencies (2), the Kisumu County special programs officer-1, managers of DPOs (3) and director of National Council for People with Disabilities-1. The researcher collected secondary data from a variety of sources. This included library books, information from journals and other government documents on issues of humanitarian policy and well-being of persons with disability in disaster context. These documents include the national Policy in PWD, Kenya constitution, 2010, UN conventions on PWD. The research instruments were trial tested in Kakamega County. Feedback from the pilot study was used to revise the instruments for final data collection. The respondents in the pilot phase were excluded during the final administration of the instruments. The questionnaires used were open and closed questions intended to capture a detailed level of content. It is chosen due to its ability to reach distant respondents hence minimized researchers influence on the respondents. It also allowed time for respondents to give well thought answers and time to respond to the items. The researcher cleaned data by listing, remove errors and check extreme values and edit to ensure conformity. The group survey data were analyzed using SPSS Version 12. The variables were subjected to descriptive statistics. The qualitative data was analyzed by consolidating emerging themes from the key informant interviews, topic analysis, and cut and paste methods on the focus group discussion transcripts. Quantitative data was analyzed using descriptive statistics such as frequencies and percentages. The researcher presented data findings in form of frequency tables, pie charts, bar graphs and narratives. Persons with disability face stigmatization in society and therefore, finding them could be difficult. This was a great challenge to the researcher to collect data. The research addressed this issue by employing snowballing. Further, the sub-county commissioners with relevant information assisted. Secondly, some respondents declined to participate due to the sensitivity of the topic. The researcher used secondary data from publication on issues of humanitarianism with regard to PWD in disaster contexts to beef up his data and information. Thirdly, language was of great challenge in remote areas or some respondents had hearing impairment since some of the respondents were unable to communicate in either English or Kiswahili. On this, the researcher engaged research assistants who speak local language and sign language interpreter for the deaf. 


\section{FINDINGS AND DISCUSSIONS}

To gather data on humanitarian policy framework, the researcher asked humanitarian and government officers to enlist inclusion aspects in the international and national humanitarian policy framework that promote the well-being of PWD. The total number of respondents was 196. Three questionnaires were not returned. Table 1 is a summary of the inclusivity indicators.

\section{Table 1. Humanitarian inclusivity aspects for PWD}

\begin{tabular}{|l|l|l|}
\hline \multicolumn{1}{|c|}{ Inclusion Aspects } & \multicolumn{1}{c|}{ Frequency } & \multicolumn{1}{c|}{ Percentage (\%) } \\
\hline Socio-economic inclusion & 39 & 20.2 \\
\hline Participation in disaster risk reduction & 20 & 10.4 \\
\hline PWD in Humanitarian Agencies & 96 & 49.7 \\
\hline
\end{tabular}

Source: Field Data, 2019

Table 1 indicates 96(49.7\%) and 39(20.2\%) of the respondents agreed that engaging PWD in humanitarian agencies and promoting their socio-economic well-being are aspects of inclusion respectively. 20(10.4\%) agreed to their inclusion into disaster risk reduction processes. PWD inclusion into humanitarian agencies would enable their participation in humanitarian participation from planning for disasters. It is at the planning stage that they are excluded from humanitarian action. UN (2016) indicates that persons with disabilities be fully included humanitarian action. It stipulates that signatories of this Charter reaffirm their determination to make humanitarian action inclusive of persons with disabilities. The international humanitarian policy recognizes the need of state parties to include persons with disability in all types of disasters ranging from natural to manmade disasters. As much as the policy is clear on protection of persons with disability in situations on risk as a result of disasters, it is not categorical on the extent of inclusivity. A critical analysis of the Charter on Inclusion of Persons with disability specifically states there should be no discrimination in humanitarian process with regard to persons with disability. It charter condemns and eliminate all forms of discrimination against persons with disabilities in humanitarian programming and policy, including by guaranteeing protection and equal access to assistance for all persons with disabilities.

On the aspect of participation and inclusion of PWD into humanitarian programs, humanitarian policies are not formulated in such a way that person with disability participate actively at all stages of humanitarian response. This means that the voice of PWD does not inform practices of humanitarian agencies that need to protect them in disaster situations. In an FDG interview, a PWD argued:

The voice of persons with disability is not heard due to being left out in humanitarian action. But there is leadership challenge since PWD in institutions do not necessarily represent interests of all persons with disability. (FDG interview held on 30 $0^{\text {th }}$ May, 2019 at Nyando)

This assertion indicates they are not consulted on how to be included into humanitarian action particularly at pre-humanitarian response stages. The capacity to address issues of disability is not available and if it was then the general support from the people in leadership has not really conceptualised the issues around disability and the importance of including them in various programming. Surpriya et al (2018) argue that disability component form part of the response team for some humanitarian organizations like KRCS. The issue is that DPO participation is limited in humanitarian action which makes it difficult to reach PWD and understand their specific needs as it were. 
The well-being of PWD can be safeguarded when awareness about disability is promoted in the community and how to handle this group of persons. Inclusivity at this stage is captured in the UN Charter on Inclusion which directs states to develop, endorse and implement policies and guidelines based on existing frameworks and standards, supporting humanitarian actors to improve inclusion of persons with disabilities in emergency preparedness and responses. For example, early warning systems accessible for people with disabilities especially people who are deaf and deaf blind is critical.

But inclusivity of PWD is affected by other related factors of socio-economic in nature. For example, participation of PWD at planning stage of humanitarian response in disaster context is directly affected by the three aspects of recognition, distribution and representation. The national humanitarian policy has aspects of inclusion of PWD into humanitarian action. For example, Kenya has enacted the National Persons with Disabilities Act 2003 and the established the 'National Council of Persons with Disabilities' (NCPWD). The National Council of Persons with Disability is responsible for the registration of PWD, administering financial support and entitlements and generally mainstreaming disability issues 'in all aspects of socio-cultural, economic and political development.

The inclusion aspect in the national humanitarian policy restricts it to disaster-free situations. The policy does not spell out how PWD would be included in humanitarian action process in disaster situations. It only concentrates on humanitarian response stage and thus it considers persons with disability as needy. Therefore, the capacity of persons with disability to contribute to humanitarian action is undermined in the national humanitarian policy. On the other hand, the Kisumu County Bill has aspects of inclusion of PWD into humanitarian action from the planning stage. This is taken care of by the Kisumu County Persons living with Disabilities Bill (Kisumu County, 2014). The Bill calls for representation of PWD in committees all levels on issue of disasters.

Further, there is an identity problem for PWD. A head of household argued that there is an assumption that by nominating someone with disability to a committee or institution then everyone disabled person is represented. Supriya et al., (2018) argue that humanitarian response consider the types of disability to cater for specific needs of persons with disability in Kisumu County. This not true from the findings since representation is more of group identity and not individual needs pegged on nature of disability. Therefore, representation of disabled persons needs to be inclusive based on the nature of disability. In an FDG interview, a PWD lamented:

We are grouped together with women, the youth as marginalized persons. This is too misleading because PWD have special needs that are incomparable with those other groups. Also, the nature of disability determines the needs and thus this needs to be put into consideration. (Interview held on $24^{\text {th }}$ May, 2019 in Nyando)

This assertion confirms that persons with disability are not identified as standalone special groups in the national humanitarian policy. Thus, this group of person's unique needs is not easily considered as stated in the 2010 Kenyan Constitution. Moreover, PWD capacity and skills were not considered in humanitarian preparedness and response mechanisms. A head of household argued that persons with disabilities are rarely included in committees and associations, or consulted in community decision-making processes. The researcher observed that Disabled Persons Organizations (DPOs) were increasingly present in county and national government committees. This provides an avenue for consultation with persons with disabilities on their needs and ideas. In many contexts, however, these groups did not represent the diversity of persons with disabilities. There is need to consider diversity in disability so that representation in various organization captures the disability aspect.

Marginalization into humanitarian action compromises PWD well-being in disasters. The researcher asked humanitarian and government officers whether the aspect of marginalization is addressed in both international and national humanitarian policy with regard to during humanitarian relief distribution. The total number of respondents was 196. Three questionnaires were not returned. 
Figure 1 indicates summary of findings on marginalization of PWD with regard to humanitarian relief distribution.

Figure 1 indicates that $(80 \%)$ of the respondents agreed that persons with disability are marginalized in disaster situations while (20\%) disagreed. This data indicates that PWD are marginalized when relief is distributed. This means that they miss out on critical relief items after disasters have struck and therefore they are not protected as envisaged in the international and national humanitarian policy framework.

Figure 1. Marginalization of PWD in humanitarian relief distribution

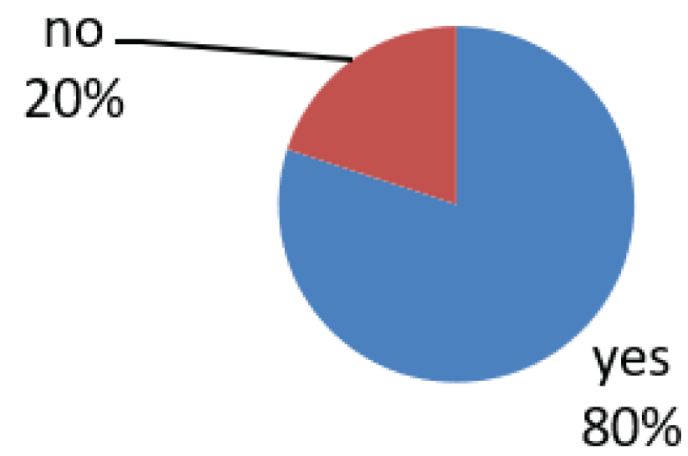

Source: Field Data, 2019

The international humanitarian policy such as the UN (2006) stipulates that partner states ensure that PWD needs is taken care of during emergencies. This not the case in Kisumu County as data indicates. On the other hand, the National Disability Policy (Republic of Kenya, 2009) stipulates that in situations of risk and humanitarian emergencies, the government takes into account the special needs for the persons with disabilities by facilitating the provision of emergency aid and supplies to them in camps and host communities. The Act indicates the desire to take care of the well-being of PWD by providing them with food, non-food items and medical supplies. The policy is silent on how PWD are supposed to access humanitarian relief even in post disaster period. However, greater marginalization is encountered when the environment is not altered to accommodate their needs in a socio-economic way.

Therefore, PWD do not access basic facilities and thus suffer and do not get services that touch on their overall wellbeing. In an interview, a head of household argued that allocation of resources end up with those deemed as able bodied who are mostly involved in these activities. The main reason for such occurrences was lack of realization on the part of humanitarian actors that some vulnerable groups like PWDs have special needs that require targeted relief distribution in disaster situations.

In both the international and national humanitarian policy framework, there is lack of structures on how PWD can access basic relief. Due to this, they become more marginalized and forgotten groups during disasters. However, the CRPD provides the most detailed set of international standards pertaining to the rights of people with disabilities in international law. It is a comprehensive convention consisting of 50 articles, which provide coverage of a full range of civil, political, economic, social, and cultural rights applicable to people with disabilities (UNCRPD, 2006). Although humanitarian policy framework stipulates that persons with disability should not be marginalized in any way, Abonyo (2015) found that during the PEV situation they experienced multiple layers of discrimination in Kisumu County. This included being disabled more with ethnicity, gender and sexual discrimination. 
As a result of these discriminative and stigmatizing factors, the able bodied persons were reluctant in according the disabled persons appropriate support and care which could assist them to cope during and after the conflict.

During disasters the well-being of PWD is affected by inadequate structures such that shelters may not be accessible to wheelchair users, and hearing-based early warning systems exclude people who are deaf. Furthermore, sexual abuse against women and girls with disabilities increases in disasters and other crisis. Twigg et al (2018) observed that marginalization is a cross cutting theme across humanitarian action cycle. During humanitarian response times, they are unlikely to receive specialized attention as required. An example is where PWD stand on the queue to access relief supplies and have to sometimes compete for supplies with rest regardless of their extra vulnerability. Supriya et al., (2018), however, found that an organization such as KRCS caters for the welfare of PWD separately while distributing relief. There is need to have clear guidelines on how to eliminate marginalization of PWD during humanitarian relief distribution in the humanitarian policy framework.

The restrictive nature of humanitarian policy framework increases barriers that exist in society towards PWD. The researcher asked humanitarian and government officers to highlight barriers to inclusion of persons with disability in humanitarian action. The total number of respondents was 196. Three questionnaires were not returned. Table 2 is a summary of findings on barriers to inclusivity into humanitarian action for PWD.

Table 2 indicate that 95(49.2\%) of the respondents agreed that persons with disability face physical barriers in disaster situation which makes it impossible for them to fully participate and benefit form

Table 2. Forms of barriers to inclusivity of PWD in humanitarian action

\begin{tabular}{|l|l|l|}
\hline \multicolumn{1}{|c|}{ Forms of Barriers } & \multicolumn{1}{c|}{ Frequency } & \multicolumn{1}{c|}{ Percentage (\%) } \\
\hline Physical & 95 & 49.2 \\
\hline Attitudinal & 78 & 40.4 \\
\hline Institutional & 39 & 20.2 \\
\hline
\end{tabular}

Source: Field Data, 2019

humanitarian activities. On the other hand, 78(40.4\%) agreed that societal attitudinal barrier hinders persons with disability from most humanitarian actions while 39(20.2\%) agreed to institutional barriers. These barriers disadvantage PWD in disaster situations which in turn affect their well-being.

The international humanitarian policy such as the UN Charter on Inclusion of PWD (2016) stipulates that persons with disabilities are disproportionately affected in situations of risk and humanitarian emergencies, and face multiple barriers in accessing protection and humanitarian assistance, including relief and recovery support. The UN Charter indicates that barriers can exclude PWD from humanitarian assistance in periods of emergencies or disasters. The Charter is clear that PWD need to be included in humanitarian planning before disasters hit. However, the policy does not identify specific barriers and provide away of eliminating them. In an FDG interview, a member argued:

Humanitarian organizations/government services are located in urban centres and rarely connect with PWD in rural areas. Most meeting of this organizations are held in accessible places for persons with disability. (Interview held on $3^{\text {rd }}$ June in Manyatta, Kisumu City)

This statement indicates that persons with disability cannot access services provided by humanitarian agencies. The organizations are stationed in urban centres which in itself is a physical barrier since accessibility to services becomes difficult. In an interview a humanitarian officer argued 
that in as much as they are located in urban centre most of their activities take place in remote areas of Kisumu County. The national humanitarian policy such as Disability Act (2003) indicates that persons with disabilities are entitled to have a barrier free environment to enable them to have access to buildings, road and other social amenities and assistive devices and other equipment to promote their mobility. Section 22(1) requires that buildings be adapted to suit persons with disabilities (Government of Kenya, 2003). The policy is general and does not address the same element in periods of disasters and therefore restrictive with regard to protection of PWD in disaster situations.

Secondly, attitudinal barriers emanate from socio-cultural beliefs. For example, some cultural beliefs make some families to keep their family members with disabilities at home. These negative attitudes are caused by a misconception about disability. Therefore, attitudinal barrier can prevent persons with disability accessing humanitarian services. In an FDG interview, a DPO member lamented:

Some parents hide a child with a disability at home because they think that disability is a source of shame or witchcraft. (Interview held on $22^{\text {nd }}$ of May, 2019 in Nyando area of Kisumu County)

This assertion indicates attitudinal barrier that exist in society makes it difficult for PWD to benefit from humanitarian services that touch on their well-being. It was noted that cultural beliefs among residents of Kisumu County.

Lastly, institutional barriers include laws, policies and procedures which can prevent persons with disability from being protected in disaster situations. Such barriers segregate people with disabilities from being employment in humanitarian or government organizations. However, CBM (2018) findings indicate that some humanitarian organizations have drafted inclusive humanitarian programs for persons with disability. The study indicates that the KRCS humanitarian response team had persons with disability. The researcher sought to know factors that contribute to barriers that jeopardize the well-being of person with disability in disaster situation.

\section{CONCLUSION}

This paper concludes that the international humanitarian policies, as well as national humanitarian policies are restrictive in nature since they limit how PWD are supposed to be protected in disasters and thus exclude PWD into humanitarian action. The reason is that they lack implementation or enforcement mechanisms to support the wellbeing of persons with disability in disasters. Moreover, the international humanitarian policy does not recognize some small-scale disasters such as political violence as situations of risk. The national humanitarian policy, on the other hand, does not specify situations of risk. 


\section{REFERENCES}

Abonyo, M. (2015). Armed Conflict And Coping Mechanisms Of Disabled Persons: A Case Study of Conflict in Kisumu, 2007 - 2013. Nairobi: Human Rights Watch.

Government of Kenya. (2003). Disability Act. Nairobi: Ministry for Special Programmes.

Government of Kenya. (2009). Draft National Policy for Disaster Management in Kenya, February 2009. Nairobi: Ministry of State for Special Programmes.

Government of Kenya. (2009). Draft National Policy for Disaster Management in Kenya, February 2009. Ministry of State for Special Programmes.

International, C. B. M. (2018). Humanitarian inclusion standards for older people and people with disabilities. Geneva: Age and Disability Consortium Charter on Inclusion of Persons with Disabilities in Humanitarian Action (23 and 24 May 2016). Retrieved from http://humanitariandisabilitycharter.org/

Janzen, A., \& Carter, M. (2012). The Impact of Micro insurance on Asset Accumulation and Human Capital Investments: Evidence from a Drought in Kenya. Working Paper. Nairobi: International Livestock Research Institute Publications.

Nyakundi, H., Mogere, S., \& Yitambe, A. (2010). Community perceptions and response to flood risks in Nyando District, Western Kenya. Journal of Disaster Risk Studies, 3(1), 346-366.

Supriya, A., \& Rhea, B. (2018). Good practice guide: Embedding inclusion of older people and people with disabilities in humanitarian policy and practice. Oxford Brookes University Publication.

Twigg, J. (2014). Attitude before method: Disability in vulnerability and capacity assessment. Disasters, 38(3), 465-482. doi:10.1111/disa.12066 PMID:24905706

United Nations Convention for Rights of Persons with Disability. (2006). Convention on the Rights of Persons with Disabilities and Optional Protocol. New York: UN. www.un.org/disabilities/documents/convention/ convoptprot-e.pdf 